\title{
A THERMOSTABILE, HEMOLYTIC PRECIPITATE FROM NUTRIENT BROTH.
}

EDWIN O. JORDAN.

IN the ordinary technique of preparing nutrient broth the fresh beef infusion is heated, filtered to remove the coagulated albuminous matter, titrated and then brought to the phenolphthalein neutral point. The flocculent precipitate that is thrown down on neutralization is commonly assumed to be in part albuminous, and some writers even refer to it definitively as "acid albumin." The precipitate begins to form at about the phenolphthalein neutral point, and is deposited abundantly when the reaction is made -1.0 to $-2.0{ }^{1} \quad$ Microscopic examination of the amorphous-looking precipitate shows it to be composed of a mass of fine, sharp, interlacing crystals. If the broth is made quite alkaline (e. g. -2.0 to -4.0 ), with either sodium, potassium or ammonium hydroxid, and the precipitate that at once forms immediately filtered off, large well-defined crystals develop in the broth on standing.

As a matter of fact the whole precipitate, after being washed with distilled water or 0.85 per cent $\mathrm{NaCl}$ solution does not give the biuret reaction or respond to any of the usual tests for proteid. So far as these tests indicate, the substance thrown down by the adding of alkali is entirely of a non-proteid nature.

The whole precipitate when thoroughly washed and suspended in 0.85 per cent $\mathrm{NaCl}$ solution is hemolytic for the corpuscles of the dog, rabbit and other animals.

When the reaction of the broth is made -2.0 , the precipitate deposited has a slightly brownish tinge. If, however, the broth is first neutralized and the resultant precipitate removed, and the fluid is then made alkaline $(-2.0)$ a second precipitate is formed composed of large white crystals. Both the whole precipitate (at the neutral point or at -2.0 ) and the purer precipitate after frac-

1 Report of Committee on Standard Methods of Water Analysis, Supplement No. 1, Jour, Infect. Dis., 1905, p. 106. 
tional removal are hemolytic in substantially equal degree. Analyses show that the precipitates are almost identical in composition. The first precipitate, deposited at about the neutral point, owes its brown color to a small amount of iron salts; there is also a little calcium in the first deposit. The purer crystalline substance deposited in the slightly alkaline broth on standing has been subjected to thorough qualitative and quantitative analysis with the result that it has been found to be practically pure magnesium-ammonium-phosphate $\left(\mathrm{MgNH}_{4} \mathrm{PO}_{4}\right)$. This substance is also the main ingredient of the deposit thrown down at the neutral point. Experiments with the chemically pure salt leave no doubt that the hemolytic property of the precipitate is due to the presence of the magnesium-ammonium-phosphate.

The salt is very slightly soluble in cold water or $\mathrm{NaCl}$ solution, and after long contact with it the supernatant fluid has practically no hemolytic effect. On heating some solution occurs.

If $0.05 \mathrm{gm}$. of this precipitate is evenly suspended in 5 c.c. of 0.85 of $\mathrm{NaCl}$ solution and this suspension is diluted to 1 to 100 , it is found that 0.1 c.c. of this dilution will completely hemolyze the standard suspension of dog's corpuscles. ${ }^{1}$ Chemically prepared magnesium-ammonium-phosphate gives the same results. Both the $\mathrm{Mg}$ and the $\mathrm{PO}_{4}$ ion are devoid of hemolytic power and the inference is strong that the active factor in hemolysis by magnesium-ammonium-phosphate is the $\mathrm{OH}$ ion. In confirmation of this view may be mentioned the selective action upon dog corpuscles shown by the writer to be manifested by the hydroxyl ion. ${ }^{2}$ A similar sensitiveness exists on the part of canine corpuscles towards the precipitate under consideration. The serum of a normal rabbit protects canine corpuscles against the action of alkali. Thus in one experiment 0.3 c.c. of normal rabbit serum protected canine corpuscles completely against the lytic dose of alkali and precisely the same amount of serum also protected against the lytic dose of the precipitate suspended in $\mathrm{NaCl}$ solution; in each case 0.2 c.c. of the serum failed to confer complete protection.

Many bacteria produce in broth cultures a degree of alkalinity quite sufficient to precipitate magnesium-ammonium-phosphate.

1 Jour. Med. Research, 1903, N. S. 5, p. 33.

2 Ibia., p. 31 . 
B. pyocyaneus, for example, in broth with an initial reaction of $+\mathbf{1 . 0}$ will in a few days change the reaction to the alkaline side of the phenolphthalein neutral point and in a longer period will often make the reaction -3.0 to -4.0 . The diphtheria bacillus can likewise alter the reaction of broth so that crystals of magnesium. ammonium-phosphate are formed.

These facts bear to some extent on the work with bacterial hemolysins. Some investigators who have worked with these substances state that the filtrate from bacterial cultures is less strongly hemolytic than the cultures themselves, and from this they have concluded that the hemolytic substance was "closely bound to the bacterial cell." It is evident from the foregoing that the sediment in alkaline bacterial cultures contains a mineral substance capable in fine suspension of producing hemolysis.

\footnotetext{
1 Bullock ANd Hunter, Centralbl. f. Bakt., 1900, 28, p. 865.
} 